\title{
Mild Skin Heating Evokes Warmth Hyperknesis Selectively for Histaminergic and Serotoninergic Itch in Humans
}

\author{
Daniele RICCIO, Hjalte Holm ANDERSEN and Lars ARENDT-NIELSEN \\ Center for Neuroplasticity and Pain, SMI, Department of Health Science and Technology, Faculty of Medicine, Aalborg University, Aalborg, \\ Denmark
}

\begin{abstract}
Chronic itch can severely affect quality of life. Patients report that their chronic itch can be exacerbated by exposure to warm conditions ("warmth hyperknesis"). The aim of this mechanistic study was to investigate the effect of mild heating of the skin in humans on various experimental models of itch. A total of 18 healthy subjects were recruited to the study. Itch was provoked by histamine, serotonin, or cowhage in 3 different sessions. The provoked area was heated with an infrared lamp, and the skin temperature was either not altered, or was increased by $4^{\circ} \mathrm{C}$ or $7^{\circ} \mathrm{C}$. Subsequent to induction of itch, the itch intensity was recorded for $\mathbf{1 0}$ min while the skin was heated continuously throughout the entire period of itch induction. Heating the skin resulted in a significant increase in itch intensity when provoked by histamine or serotonin. It is possible that thermoception and pruriception interact and selectively produce a higher itch intensity in histaminergic and serotoninergic itch.
\end{abstract}

Key words: itch; warmth; hyperknesis; histamine; serotonin; cowhage.

Accepted Dec 7, 2021; Epub ahead of print Jan 27, 2022

Acta Derm Venereol 2022; 102: adv00649.

DOI: $10.2340 /$ actadv.v102.173

Corr: Lars Arendt-Nielsen, Faculty of Medicine, Aalborg University, Fredrik Bajers Vej, D3-212, DK-9220 Aalborg East, Denmark. E-mail: LAN@hst. aau.dk

$\mathrm{C}$ hronic itch can severely affect patients' lives and is very burdensome. Two of the most important features widely exhibited by patients with chronic itch are alloknesis (itch caused by a stimulus that normally does not evoke itch) and hyperknesis (a normal itchy stimulus evokes a stronger and/or longer-lasting itch response). Despite the intense search for new treatments and therapies, they are still largely ineffective for the majority of patients with chronic itch $(1,2)$. This is partly due to the lack of comprehension of the basic mechanisms of inhibiting or facilitating itch and methods to exploit these mechanisms in humans.

In recent years, studies have focused on the relationship between heat and itch, and shown that heat in the noxious range can inhibit experimentally evoked itch to various degrees (3-5). Unfortunately, applying heat in the noxious range ( $>$ approximately $45^{\circ} \mathrm{C}$ ) as a treatment modality is not a feasible solution, due to the potential skin damage that prolonged exposure may cause. Conversely, animal

\section{SIGNIFICANCE}

Chronic itch affects millions of people worldwide, drastically decreasing their quality of life. In warm conditions itch can be exacerbated, but it is unclear to what extent this phenomenon occurs and if elucidating this effect might be useful in the development of new treatments for itch. This study investigated the effect of mild heating of the skin on various modalities of itch. Itch sensation was increased in 2 out of 3 different modalities when the skin was mildly heated. Moreover, itch was increased at different temperatures. These insights may be of use in developing new therapies for chronic itch.

studies have shown that innocuous warming of the skin can exacerbate scratching behaviour (6). This evidence has been also confirmed in patients with inflammatory itch disorder (7). Such a mechanism is usually referred to as "warmth hyperknesis" (7-9). It has been shown that various cutaneous receptors are responsible for the warmth sensation, e.g. the transient receptor potential vanilloid (TRPV) receptors family, specifically TRPV3 and TRPV4 (10-14). However, the mechanisms behind these independent observations are unknown.

In this regard, there is a need to study the underlying mechanisms between innocuous heat perception and itch perception, in order to find suitable receptor targets or devices for new treatment options.

Three experimental models used widely in preclinical studies are histaminergic itch, serotoninergic itch, and cowhage-induced itch (15-18). Based on the data and experiences from clinical observations, as well as patients' responsiveness to treatments, it is of crucial importance to use different models, as, to date, none of these is similar enough to the features observed in patients with chronic itch (19).

The aim of this study was to evaluate the effect of mild skin heating on itch, using 3 human itch surrogates induced by histamine, serotonin, and cowhage (nonhistaminergic itch).

\section{MATERIALS AND METHODS}

\section{Experimental design}

A total of 18 healthy subjects participated in the current study (10 males; $25 \pm 0.53$ years of age). The study was subdivided into 3 sessions of $1.5 \mathrm{~h}$ each, in which participants underwent a single 
A Randomized between sessions

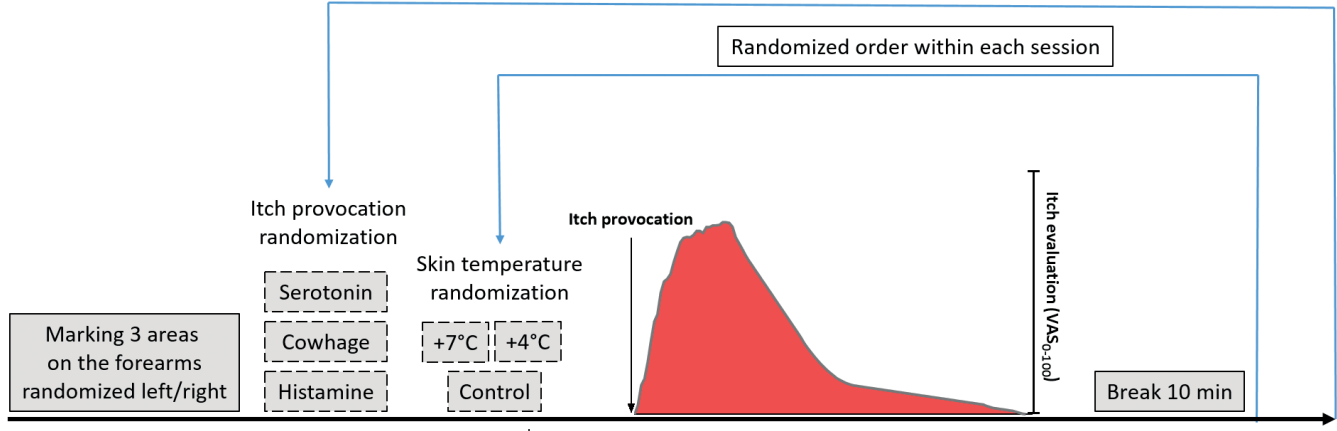

B

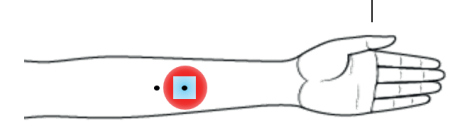

-

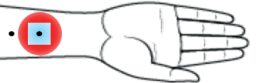

Skin warming area, +4 or $+7^{\circ} \mathrm{C}$ Itch induction site

- Temperature measurament site
Fig. 1. (A) Schematic representation of the experiment. All itch provocations were randomized for placement and order. The order of the different skin temperature conditions was also randomized. (B) Schematic representation of the localization of itch provocation site, skin warming areas and temperature measurement sites. Control: unaltered skin temperature; $+4^{\circ} \mathrm{C}$ : skin temperature increased by $4^{\circ} \mathrm{C} ;+7^{\circ} \mathrm{C}$ : skin temperature increased by $7^{\circ} \mathrm{C}$. itch provocation, different in each session (Fig. 1A). At the start of the first session, it was briefly explained to the participants that a script to provide specific instruction on the experiment would be used throughout the entire study. This was done to reduce to a minimum the bias the researcher might involuntarily exert on the participant. In each session, 3 areas were marked on the volar forearms: 2 on 1 forearm, and 1 on the other forearm, randomized between left and right (Fig. 1B).

The study was approved by the regional ethics committee (Denmark, Nordjylland number N-20180035). All participants provided signed informed consent before participation and could withdraw from the study at any time.

\section{Itch provocation}

Itch was provoked by 3 different substances and methods: histamine, serotonin, and cowhage. Histaminergic itch was evoked as described previously (5). Briefly, a drop of histamine chloride (1\%; Diagenics, Milton Keynes, UK) was applied in the designated area on the skin in the centre of the area and punctured with a standard skin-prick test needle (Diagenics, Milton Keynes, UK). This method is safe, and ensures the development of itch sensation coupled with development of a wheal $(20,21)$.

Serotoninergic itch was evoked using the iontophoresis technique, where an area of skin next to the area marked for itch induction was treated with a special abrasive cream, and rubbed with a cotton swab to reduce impedance (Nuprep, Weaver and Co., Aurora, CO, USA). The conductive pad was applied to the same area, connected to the cathode cable of the iontophoreser (Moor Instruments, Axminster, Devon, UK). The ion chamber was then placed in the marked area and filled with $150 \mu 1$ serotonin solution $(17 \mathrm{mg} / \mathrm{ml}$ in $2.5 \%$ methylcellulose; Sigma Aldrich, Søborg, Denmark). Iontophoresis was performed at $0.250 \mathrm{~mA}$ for $120 \mathrm{~s}(22,23)$.

Cowhage-induced itch was evoked by application of 35-40 cowhage spicules on the skin; as described previously $(5,24,25)$.

\section{Skin temperature evaluation}

The skin temperature was measured with an infrared thermometer pointed at the desired spot from a distance of approximately 30 $\mathrm{cm}$. Measurements were performed at the start of the study at 2 points (at the itch application site and $4 \mathrm{~cm}$ from the application site; Fig 1B); subsequently, the temperature was evaluated at both sites every minute and recorded.

\section{Skin warming}

The skin was warmed using an infrared lamp pointed directly at the skin. The distance from the lamp to the skin was adjusted accordingly, in order to maintain a constant target temperature, and always at least $20 \mathrm{~cm}$ away from the skin to avoid risk of burning. This procedure was started prior to itch induction and the heating was subsequently maintained for $10 \mathrm{~min}$. The temperatures to which the skin was heated were randomized between the left and right arms, as was a control/placebo condition in which the skin was not heated (Fig. 1B). Two different target temperatures were chosen: $+4^{\circ}$ and $+7^{\circ} \mathrm{C}$ above the ambient skin temperature $\left(\sim 32^{\circ} \mathrm{C}\right)$, as recorded beforehand (Fig. 2).

\section{Itch intensity assessment}

The itch intensity was assessed continuously using a digital-visual analogue scale (VAS; eVAS Software; Aalborg University, Aalborg, Denmark) and sampled every $5 \mathrm{~s}(0.2 \mathrm{~Hz})$ by the software. This scale ranges from 0 to 100 , where 0 indicates "No itch" and 100 "Worst imaginable itch". The participants were instructed to rate their itch sensation continuously after itch induction. The recording was stopped by the experimenter $10 \mathrm{~min}$ after itch provocation.

\section{Blood skin perfusion analysis}

Blood skin perfusion was analysed by full-field laser perfusion imaging (FLPI; Moor Instruments). Briefly, exactly 10 and 15 min after the start of the itch induction, the FLPI was placed approximately $40 \mathrm{~cm}$ above the forearm and an image was captured. The images were analysed using proprietary software (MoorFLPI 2.0 Review Version 5.0; Moor Instruments), where the region of interest (ROI) was outlined (the $3 \times 3 \mathrm{~cm}$ area marked for itch induction) and then the mean perfusion was calculated and successively recorded.

\section{Statistical analysis}

The data collected for itch intensity in the form of temporal profiles were used to calculate the area under the curve (AUC) for every condition, using the trapezoidal method explained by Bailer (26). The temporal profiles were subdivided into smaller windows of 2 min each. Subsequently, the conditions (control, $+4^{\circ} \mathrm{C}$, and $+7^{\circ} \mathrm{C}$ ) 

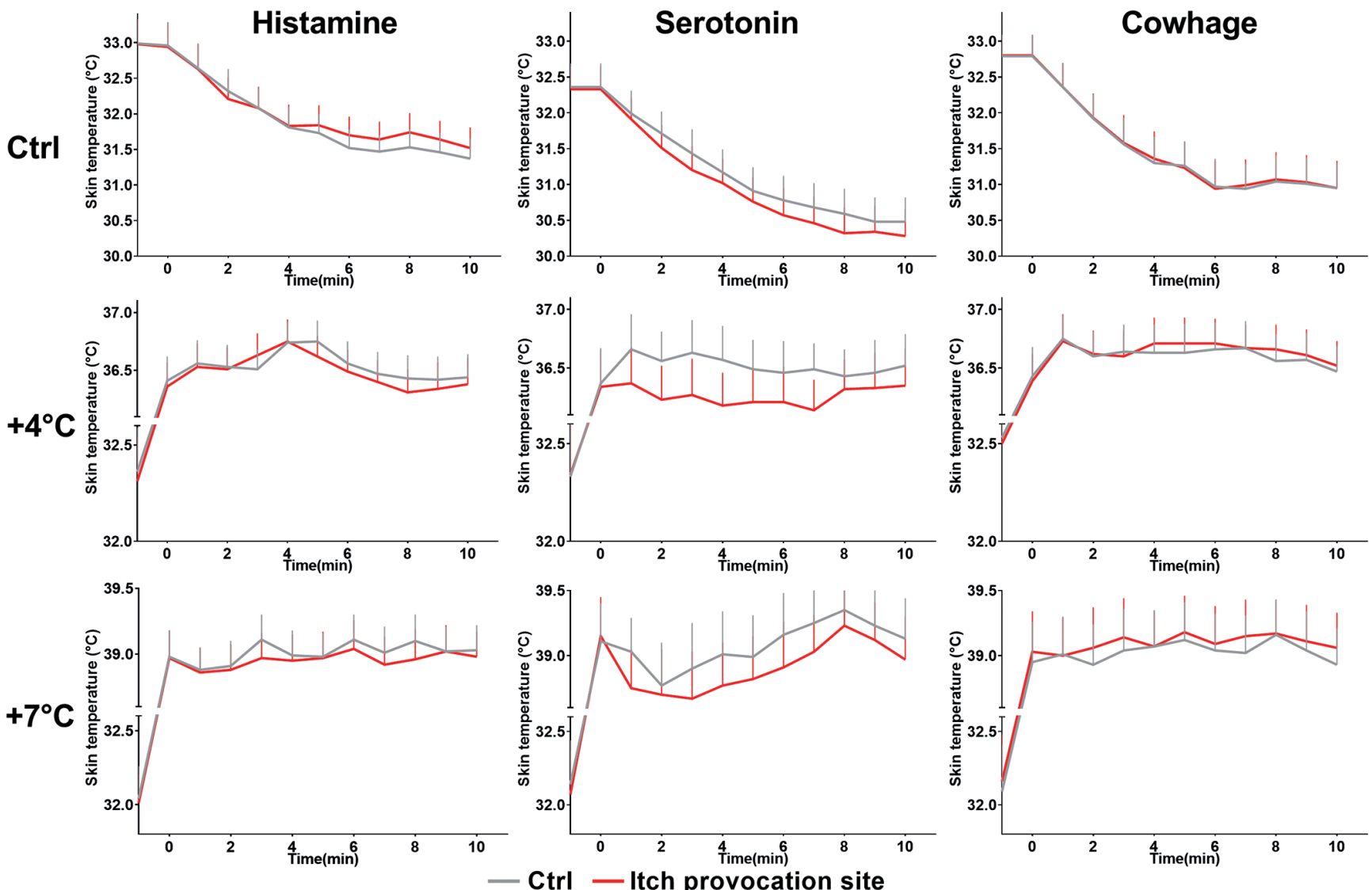

Fig. 2. Skin temperature analysis. The temperature was measured in 2 different point itch provocation sites (red lines) and control sites (grey lines) every minute, starting before the skin was heated and up to $10 \mathrm{~min}$ after itch induction. to indicates the time-point when itch was provoked. $+4^{\circ} \mathrm{C}$ and $+7^{\circ} \mathrm{C}$ indicate how much the skin was heated before the itch induction.
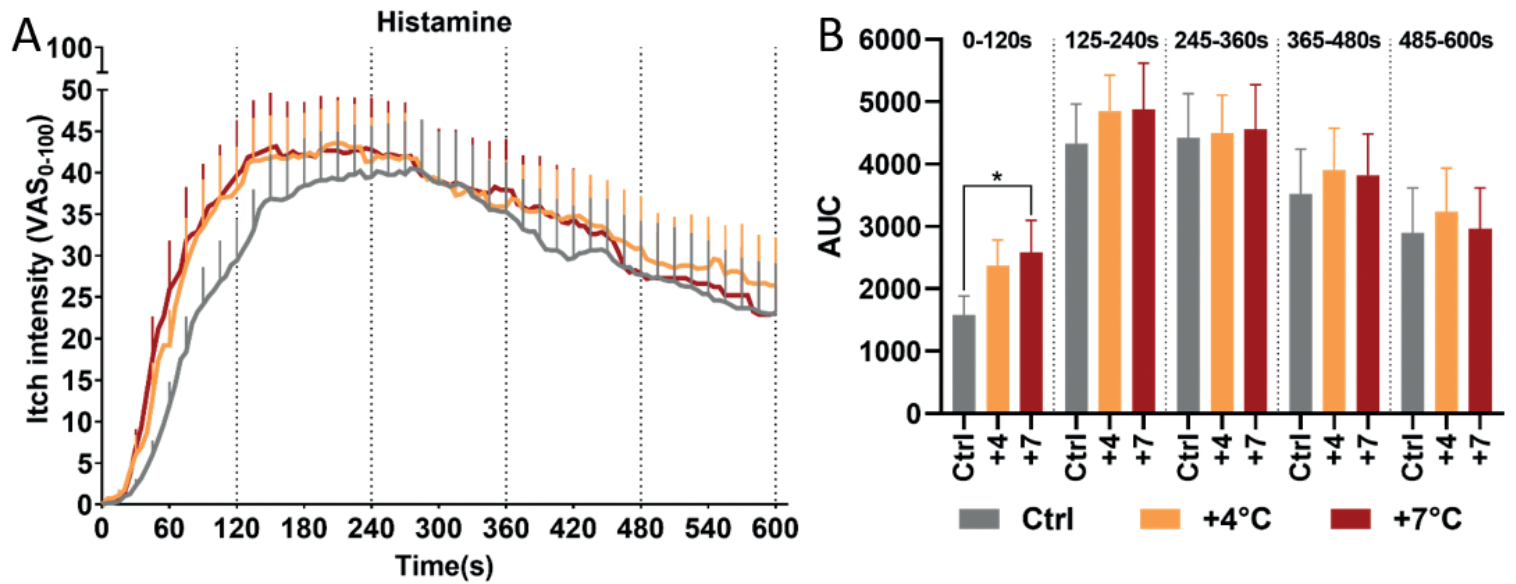

\begin{tabular}{|l|c|c|c|c|c|c|c|c|c|c|}
\hline Histamine & \multicolumn{2}{|c|}{$0-120 \mathrm{~s}$} & \multicolumn{2}{c|}{$125-240 \mathrm{~s}$} & \multicolumn{2}{c|}{$245-360 \mathrm{~s}$} & \multicolumn{2}{|c|}{$365-480 \mathrm{~s}$} & \multicolumn{2}{|c|}{$485-600 \mathrm{~s}$} \\
\hline $\mathrm{Ctrl}$ vs $+4^{\circ} \mathrm{C}$ & 49,88 & 0,0626 & 12,09 & 0,6855 & 1,72 & $>0.9999$ & 10,98 & 0,8994 & 12,19 & $>0.9999$ \\
\hline $\mathrm{Ctrl}$ vs $+7^{\circ} \mathrm{C}$ & 63,10 & 0,0422 & 12,70 & 0,7177 & 2,85 & $>0.9999$ & 8,45 & $>0.9999$ & 2,62 & $>0.9999$ \\
\hline$+4^{\circ} \mathrm{C}$ vs $+7^{\circ} \mathrm{C}$ & 8,82 & $>0.9999$ & 0,55 & $>0.9999$ & 1,11 & $>0.9999$ & $-2,28$ & $>0.9999$ & $-8,53$ & $>0.9999$ \\
\hline
\end{tabular}

Fig. 3. Histaminergic itch analysis and comparisons between the different conditions for every time window. (A) Temporal profiles of itch ratings starting from immediately after the itch provocation up to 10 min later. Dotted lines represent the division in the different time window analysed. (B) Area under the curve (AUC) analysis of the itch intensity evoked in different conditions. (C) Table showing the results of the statistical analysis. In each cell the percentage change is indicated on the right and the $p$-value on the left. Significant $p$-values are indicated in red. $* p<0.05$. VAS: visual analogue scale; $+4^{\circ} \mathrm{C}$ and $+7^{\circ} \mathrm{C}$ indicate how much the skin was heated before itch induction. 
A

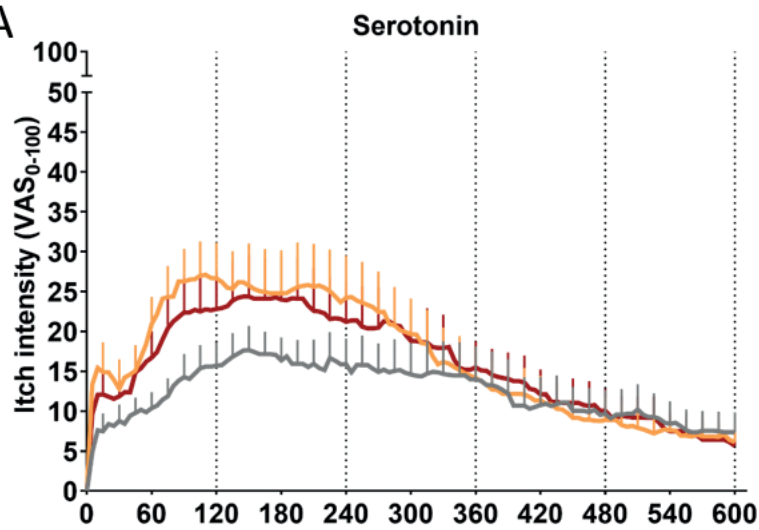

Time(s)

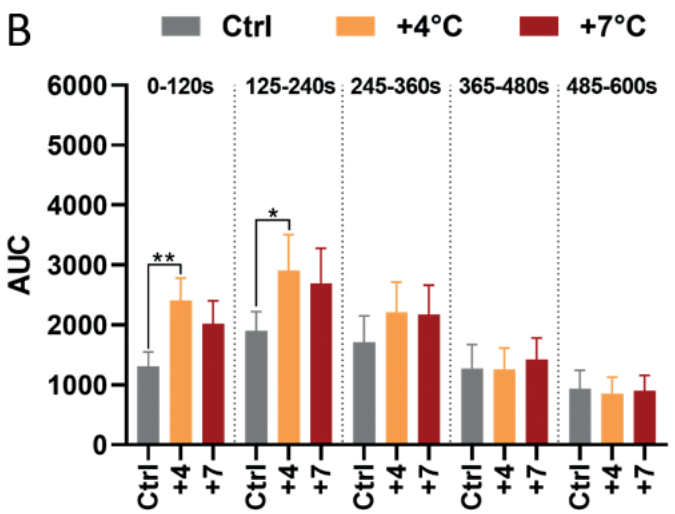

\begin{tabular}{|c|c|c|c|c|c|c|c|c|c|c|}
\hline Serotonin & \multicolumn{2}{|c|}{$0-120 \mathrm{~s}$} & \multicolumn{2}{|c|}{$125-240 s$} & \multicolumn{2}{|c|}{$245-360 s$} & \multicolumn{2}{|c|}{$365-480 \mathrm{~s}$} & \multicolumn{2}{|c|}{ 485-600s } \\
\hline $\mathrm{Ctrl}$ vs $+4^{\circ} \mathrm{C}$ & 83,27 & 0,0024 & 53,07 & 0,0369 & 28,97 & 0,5077 & $-1,27$ & $>0.9999$ & $-9,35$ & $>0.99$ \\
\hline $\mathrm{Ctrl}$ vs $+7^{\circ} \mathrm{C}$ & 54,15 & 0,1847 & 41,88 & 0,278 & 27,08 & $>0.9999$ & 11,73 & $>0.9999$ & $-4,15$ & $>0.995$ \\
\hline$+4^{\circ} \mathrm{C}$ vs $+7^{\circ} \mathrm{C}$ & $-15,89$ & 0,4873 & $-7,31$ & $>0.9999$ & $-1,46$ & $>0.9999$ & 13,17 & $>0.9999$ & 5,74 & $>0.999$ \\
\hline
\end{tabular}

Fig. 4. Serotoninergic itch analysis and comparisons between the different conditions for every time window. (A) Temporal profiles of itch ratings starting from immediately after itch provocation up to $10 \mathrm{~min}$ later. Dotted lines represent the division in the different time window analysed. (B) Area under the curve (AUC) analysis of the itch intensity evoked in different conditions. (C) Table showing results of statistical analysis. In each cell the percentage change is indicated on the right and the $p$-value on the left. Significant $\mathrm{p}$-values are indicated in red. $* p<0.05, * * p<0.01 ;$ VAS: visual analogue scale; $+4^{\circ} \mathrm{C}$ and $+7^{\circ} \mathrm{C}$ indicate how much the skin was heated before itch induction.

were compared with each other within the same time window, to elucidate the differences occurring in all phases of development of itch sensation. Repeated-measure analysis of variance (ANOVA) was used for statistical comparisons of itch intensity temporal profiles and the mean of the skin blood perfusion for each region of interest, using Bonferroni as post hoc test. $p<0.05$ was considered significant.

\section{RESULTS}

\section{Effect of mild skin warming on itch intensity}

Histaminergic itch increased significantly when the skin was heated by $7^{\circ} \mathrm{C}$ in the first $2 \min (63 \%, p=0.0422$; Fig. 3). No significant difference in itch intensity was reported for conditions in which the temperature was increased by $4^{\circ} \mathrm{C}$, or during later phases.

Serotoninergic itch increased significantly when the skin was heated by $4^{\circ} \mathrm{C}$ in the first 4 min compared with the control condition ( $0-2$ min: $83 \%, p=0.0024,2-4$ $\min : 53 \%, p=0.0369 ;$ Fig. 4). No significant difference in itch intensity was reported when the temperature was increased by $7^{\circ} \mathrm{C}$, or during later phases.

Itch intensity evoked by cowhage on skin warmed by either $4^{\circ} \mathrm{C}$ or $7^{\circ} \mathrm{C}$ did not differ from the control condition (Fig. 5).

\section{Skin temperatures and blood flow analysis}

The target temperatures achieved by skin warming were constant and did not vary significantly across time or method of itch induction (Fig. 1B and Fig. 2). For the control condition, skin temperature decreased by $1.5-2^{\circ} \mathrm{C}$ following application of each pruritogen (Fig. 2, upper row).
The blood flow after the histaminergic itch induction showed no difference when the skin was heated by $4^{\circ} \mathrm{C}$ or $7^{\circ} \mathrm{C}$ compared with the control condition (Fig. 6A).

Itch induced by serotonin provoked a significant increase in skin blood flow when the skin was heated by $7^{\circ} \mathrm{C}$, but not by $4^{\circ} \mathrm{C}$, compared with the control condition. This was observed both 10 and 15 min after the induction of itch $(22 \%, p=0.0435,28 \%, p=0.0006$, respectively; Fig. 6B).

Cowhage-induced itch provoked an increased blood skin flow when the skin was heated by $4^{\circ} \mathrm{C}$ and $7^{\circ} \mathrm{C}$ compared with the control condition, 10 min after the induction of itch $(28 \%, p=0.0227,59 \%, p=0.0006$, respectively, Fig. 6C). However, 15 min after the itch provocation there was a significant difference only when the skin was heated by $7^{\circ} \mathrm{C}(85 \%, p=0.0113$, Fig. $2 \mathrm{C})$. A significant difference was also found when the compared skin temperature increased by $4^{\circ} \mathrm{C}$ and $7^{\circ} \mathrm{C} 10$ min after induction of itch $(25 \%, p=0.0188$, Fig. $6 \mathrm{C})$.

Notably, there was no correlation between skin blood flow and itch intensity, expressed either as AUC or as mean VAS score (data not shown).

\section{DISCUSSION}

This study showed that histaminergic and serotonergic experimentally provoked itch could be facilitated by warmth stimulation $\left(+4^{\circ} \mathrm{C}\right.$ and $+7^{\circ} \mathrm{C}$ above normal skin temperature), whereas cowhage-induced itch was not altered by the skin warming.

As observed in many previous studies, the normal skin temperature is approximately $32^{\circ} \mathrm{C}(4,27-30)$. There- 

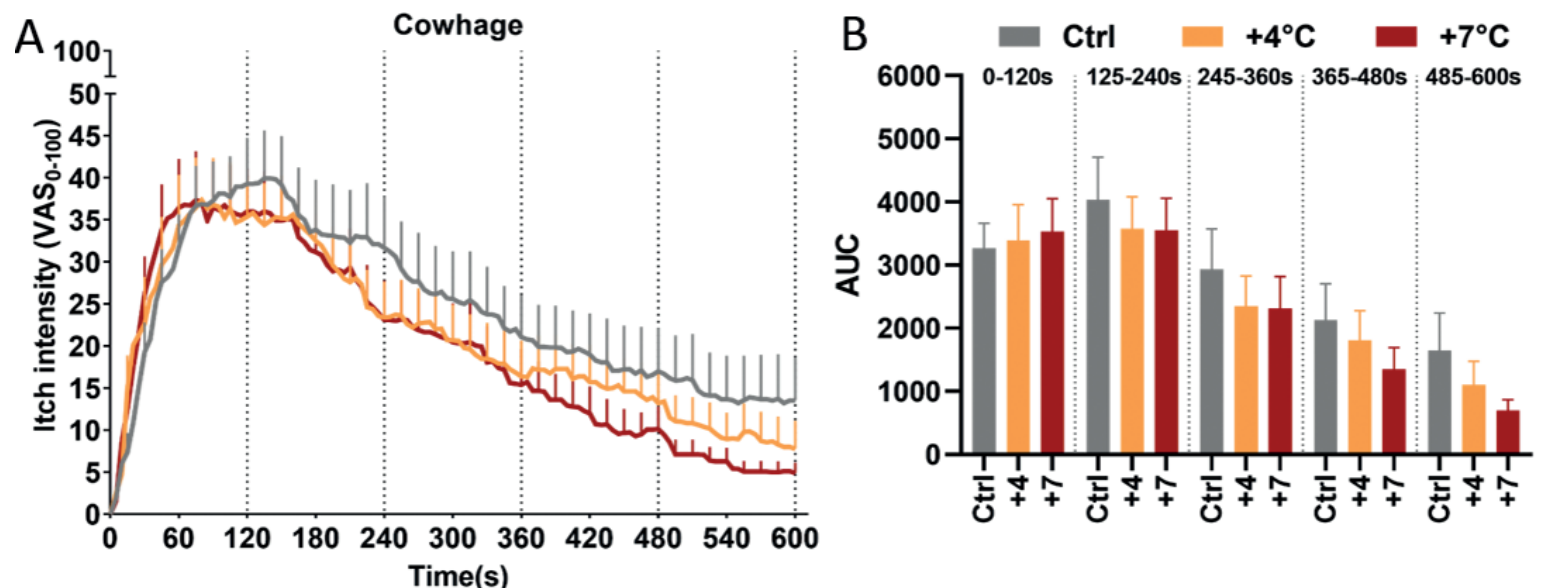

\begin{tabular}{|c|c|c|c|c|c|c|c|c|c|c|}
\hline \multirow[t]{2}{*}{ Cow } & \multicolumn{2}{|c|}{$0-120 \mathrm{~s}$} & \multicolumn{2}{|c|}{$125-240 \mathrm{~s}$} & \multicolumn{2}{|c|}{$245-360 \mathrm{~s}$} & \multicolumn{2}{|c|}{$365-480 \mathrm{~s}$} & \multicolumn{2}{|c|}{$485-600 \mathrm{~s}$} \\
\hline & 4,02 & $>0.9$ & $-11,58$ & $>0.999$ & $-20,06$ & \begin{tabular}{|l|}
0,9027 \\
\end{tabular} & $-15,00$ & $>0.999$ & $-32,53$ & $>0.95$ \\
\hline Ctrlvs $+7^{\circ} \mathrm{C}$ & 8,37 & 0.99 & $-12,09$ & 0,795 & $-21,29$ & 0,6382 & $-36,43$ & 0,2505 & $-57,46$ & 0.55 \\
\hline & 4,18 & 00 & & & & 0 & 521 & 7563 & & \\
\hline
\end{tabular}

Fig. 5. Cowhage-induced itch analysis and comparisons between the different conditions for every time window. ( $A$ ) Temporal profiles of itch ratings starting from the moment after the itch provocation up to 10 min later. Dotted lines represent the division in the different time window analysed. (B) Area under the curve (AUC) analysis of the itch intensity evoked in different conditions. (C) Table showing the results of the statistical analysis. In each cell, the percentage change is indicated on the right and the $p$-value on the left. VAS: visual analogue scale; $+4^{\circ} \mathrm{C}$ and $+7^{\circ} \mathrm{C}$ indicate how much the skin was heated before itch induction.

fore, the skin temperatures used in this study were $32^{\circ} \mathrm{C}$ (normal/control), $\approx 36^{\circ} \mathrm{C}\left(+4^{\circ} \mathrm{C}\right)$ and $\approx 39^{\circ} \mathrm{C}\left(+7^{\circ} \mathrm{C}\right)$. In the control condition the temperature decreased by $1.5-2^{\circ} \mathrm{C}$ throughout the $10 \mathrm{~min}$, both at the injection site and 4 $\mathrm{cm}$ distant from it (control site). This was considered normal, due to the long exposure to room temperature of the volar aspects of the forearm.

The histaminergic itch was enhanced during the onset phase when the skin temperature was increased by $7^{\circ} \mathrm{C}$, whereas the serotoninergic itch was enhanced by an increase in temperature of $4^{\circ} \mathrm{C}$.

This line of evidence suggests a modulatory role of innocuous heat on itch sensation. It has been widely re- ported that noxious heat (i.e. $\geq 45^{\circ} \mathrm{C}$ ) can inhibit and, in certain conditions, even resolve the itch sensation (3-5).

\section{Modulation of itch intensity}

These results are not in line with an animal study demonstrating that solely serotoninergic itch has been enhanced by warmth (6). There is no clear explanation for this discrepancy, but a few considerations can be suggested.

It is well known that thermal perception relies on the TRPV receptors family. Specifically, TRPV1 has been widely associated with the perception of higher temperature evoked pain (activated by temperature $\geq 42^{\circ} \mathrm{C}$;

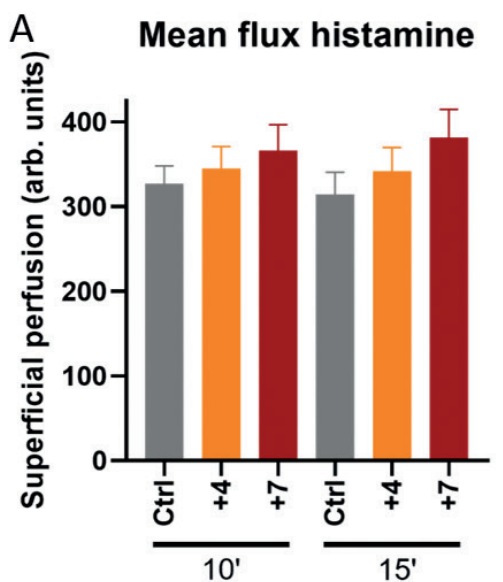

Minutes after itch induction

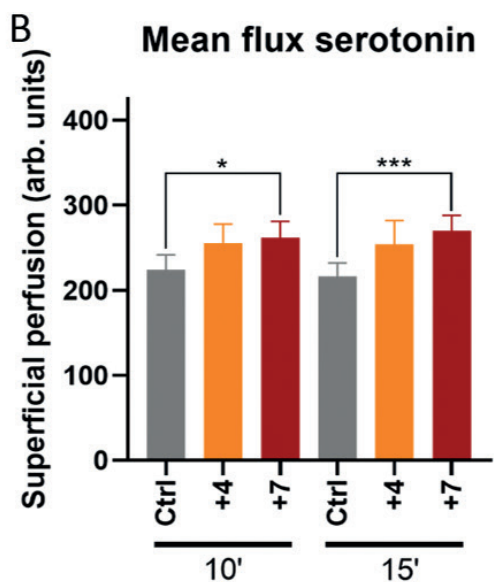

Minutes after itch induction

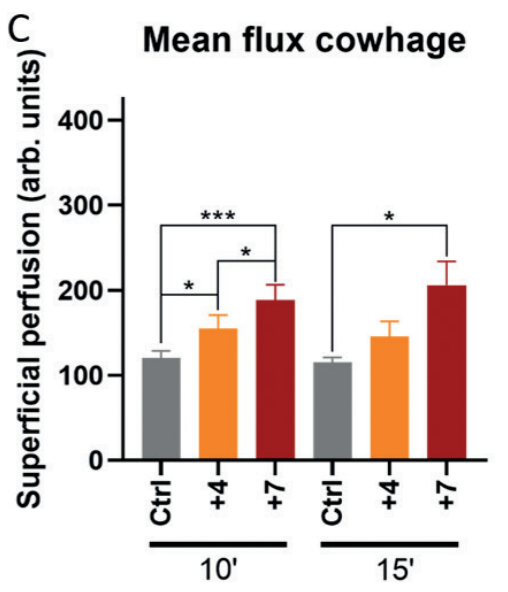

Minutes after itch induction

Fig. 6. Superficial skin blood perfusion analysis. The data collected are indicated on the left and right side of all the graphs, respectively 10 and 15 min after the itch induction. The data are indicated as arbitrary units and refer to the mean flux of the superficial skin perfusion in the region of interest selected. (A) Histamine-induced itch. (B) Serotonin-induced itch. (C) Cowhage-induced itch. $* p<0.05, * * * p<0.001 ;+4^{\circ} \mathrm{C}$ and $+7^{\circ} \mathrm{C}$ indicate how much the skin was heated before itch induction. 
thermal pain threshold $\approx 45^{\circ} \mathrm{C}$ ); whereas TRPV3 and TRPV4 have been implicated with the thermal perception of temperature in the innocuous range (i.e. TRPV3 $\geq 33^{\circ} \mathrm{C}$; TRPV4 $\left.27-42^{\circ} \mathrm{C}\right)(31)$. It has also been shown how TRPV4 ablation or antagonism selectively inhibits serotoninergic itch $(11,32)$. Similarly, it has been shown that TRPV4 is involved in the histaminergic itch pathway (33). It could therefore be speculated that the effect observed on histamine- and serotonin-induced itch may be due to the interaction with TRPV4. Interaction with the innocuous warmth receptor TRPV3 cannot be ruled out.

The lack of temperature effect on cowhage-induced itch seems to indicate an insufficient (or absent) interaction between the proteinase-activated receptor 2 (PAR2) mediating this type of non-histaminergic itch and the TRPV3 and TRPV4 receptors.

However, it has been shown that activated PAR2 cooperates with TRPV3 to elicit the itch sensation (13, 14). The current data suggest that the co-activation of TRPV3 (e.g. by increasing the skin temperature) with PAR2 (e.g. evoked by mucunain released by cowhage spicules $(34,35))$ is not able to increase the itch sensation over its threshold derived from the PAR2 activation alone. Nonetheless, it is possible that PAR2 activation leads to an increased warmth sensation due to its known interaction with TRPV3 (13). However, we do not have any results to support this hypothesis and therefore we cannot rule out other possibilities.

\section{Modulation of itch intensity (onset phase)}

The warmth-evoked itch facilitation was noted particularly during the early onset phases of histaminergic and serotoninergic itch. This suggests that the receptor modulation may be more active during this initial dynamic phase, and at higher receptor activation levels a more rapid decrease was observed compared with controls. Given these premises, the data suggest that the interaction between the thermoreceptors and the itch receptors (i.e. histamine receptor and serotonin receptor) predominantly occur during the phase of increased activation, but not when stable or less activation is present. This information may be of use in the possible development of ways to counteract the clinical problem of heat-evoked itch facilitation (warmth alloknesis).

\section{Modulation of neurogenic inflammation}

The skin blood perfusion analysis revealed an increase in blood perfusion following skin warming and itch induction by cowhage (when the skin was heated by $4^{\circ} \mathrm{C}$ and $7^{\circ} \mathrm{C}$ at both time-points analysed) and serotonin (only observed when the skin was heated by $7^{\circ} \mathrm{C}$ at both timepoints). Therefore, it appears that increased blood flow is not an important feature for modulating itch provoked by cowhage and serotonin. However, due to the afore- mentioned increased blood perfusion, one can speculate that the known interaction between TRPV3 and TRPV4 with the PAR2 receptor (13) and serotonin receptors (11, 32 ), respectively, could contribute to increased blood flow despite constant itch intensity. It is known that both TRPV3 and PAR 2 are involved in inflammatory response (36-41) and the possible co-activation could at least partly be responsible for the increased skin blood flow observed. The interaction between serotonin receptors with TRPV4 has been shown, but not with TRPV3, for which there is no evidence. This could suggest that the increased blood flow observed exclusively when the skin was heated by $7^{\circ} \mathrm{C}$ (i.e. $\approx 39^{\circ} \mathrm{C}$ ), is due to a marked activation of TRPV4 (activation temperature $27-42^{\circ} \mathrm{C}(31)$ ). The lack of increase in skin blood flow with histaminergic itch between the control and the heating conditions could indicate that the histamine-induced neurogenic inflammatory increased blood flow is not enhanced by additional heating of the skin.

It is notable that these data also raise questions regarding involvement of the autonomic nervous system. It has been shown how both sympathetic and parasympathetic nervous systems are recruited in patients with chronic itch (42-44) and when itch is experimentally induced (45-47). It would be interesting to analyse how other parameters, such as heart rate variability, vasoconstriction reflexes and blood pressure, varies between the heat and no-heat conditions in this experiment. Further studies are needed to explore how the autonomic nervous system interacts with itch intensity and blood flow and such a mechanism could potentially be exploited.

\section{Study limitations}

Only 2 temperatures (other than the control condition without any external influence) were used as intermediate temperature ranges. It would still be possible to explore higher temperatures (e.g. $+9^{\circ} \mathrm{C}$ ) before the noxious level is reached. The study was designed with a singular warmth condition per forearm every session, while the control condition was randomized between the 2 forearms. Adding an extra higher temperature session could have increased the chance of interference between different conditions.

It might also have been of importance to record the provoked warmth perception/intensity during the itch provocation; however, being able to discriminate a difference in thermal sensation and, at the same time, rate changes in the itch perception/intensity would probably have reduced the accuracy of the itch ratings, on which the primary aim of this study is based.

The overall itch sensation perceived when induced by serotonin was lower compared with that induced by histamine and cowhage, leaving us with the limitation of not having comparable itch intensity among the different models. Nonetheless, the serotonin concentration (17 
$\mathrm{mg} / \mathrm{ml}$ ) used in the current study was the maximum possible, due to the intrinsic solubility of the molecule. The induction method used in this study has also been used in previous studies, achieving similar (22), or slightly higher itch intensity (23).

\section{Conclusion}

Slight increases $\left(4^{\circ} \mathrm{C}\right.$ and $\left.7^{\circ} \mathrm{C}\right)$ in skin temperature resulted in increased itch intensity when provoked by serotonin and histamine, but not when provoked by cowhage spicules (non-histaminergic itch). This evidence partly confirms recent animal studies regarding serotoninergic itch, but contradicts animal results showing no effect with histaminergic itch (6). Cowhage-induced itch intensity was not affected by warmth, but the heating caused additional increases in skin blood flow, probably due to the known interaction between PAR2 and TRPV3 receptors.

\section{ACKNOWLEDGEMENTS}

DR and LAN are part of the Center for Neuroplasticity and Pain (CNAP), which is supported by the Danish National Research Foundation (DNRF121).

The authors have no conflicts of interest to declare.

\section{REFERENCES}

1. Pereira MP, Kremer AE, Mettang T, Ständer S. Chronic pruritus in the absence of skin disease: pathophysiology, diagnosis and treatment. Am J Clin Dermatol 2016; 17: 337-348.

2. Pereira MP, Ständer S. Chronic pruritus: current and emerging treatment options. Drugs 2017; 77: 999-1007.

3. Yosipovitch G, Fast K, Bernhard JD. Noxious heat and scratching decrease histamine-induced itch and skin blood flow. J Invest Dermatol 2005; 125: 1268-1272.

4. Yosipovitch G, Duque MI, Fast K, Dawn AG, Coghill RC. Scratching and noxious heat stimuli inhibit itch in humans: a psychophysical study. $\mathrm{Br}$ ] Dermatol 2007; 156: 629-634.

5. Riccio D, Andersen HH, Arendt-Nielsen L. Antipruritic effects of transient heat stimulation on histaminergic and nonhistaminergic itch. Br J Dermatol 2019; 181: 786-795.

6. Akiyama T, Nagamine M, Davoodi A, Ivanov M, Carstens MI, Carstens E. Innocuous warming enhances peripheral serotonergic itch signaling and evokes enhanced responses in serotonin-responsive dorsal horn neurons in the mouse. J Neurophysiol 2017; 117: 251-259.

7. Goon ATJ, Yosipovitch G, Chan YH, Goh CL. Clinical characteristics of generalized idiopathic pruritus in patients from a tertiary referral center in Singapore. Int J Dermatol 2007; 46: 1023-1026.

8. Darsow U, Scharein E, Simon D, Walter G, Bromm B, Ring J. New aspects of itch pathophysiology: component analysis of atopic itch using the 'Eppendorf Itch Questionnaire.' Int Arch Allergy Immunol 2001; 124: 326-331.

9. Dawn A, Papoiu ADP, Chan YH, Rapp SR, Rassette N, Yosipovitch G. Itch characteristics in atopic dermatitis: results of a web-based questionnaire. $\mathrm{Br} J$ Dermatol 2009; 160: 642-644.

10. Kim S, Barry DM, Liu XY, Yin S, Munanairi A, Meng QT, et al. Facilitation of TRPV4 by TRPV1 is required for itch transmission in some sensory neuron populations. Sci Signal 2016; 9: ra71.

11. Akiyama T, Ivanov M, Nagamine M, Davoodi A, Carstens MI, Ikoma A, et al. Involvement of TRPV4 in serotonin-evoked scratching. J Invest Dermatol 2016; 136: 154-160.

12. Cui TT, Wang GX, Wei NN, Wang KW. A pivotal role for the activation of TRPV 3 channel in itch sensations induced by the natural skin sensitizer carvacrol. Acta Pharmacol Sin 2018; 39: 331-335.

13. Zhao J, Munanairi A, Liu XY, Zhang J, Hu L, Hu M, et al. PAR2 mediates itch via TRPV3 signaling in keratinocytes. J Invest Dermatol 2020; 140: 1524-1532.

14. Park C, Kim H, Choi Y, Chung B, Woo S-Y, Song D-K, et al. TRPV3 channel in keratinocytes in scars with post-burn pruritus. Int J Mol Sci 2017; 18: 2425.

15. Hoeck EA, Marker JB, Gazerani $P, H$. Andersen $H$, ArendtNielsen L. Preclinical and human surrogate models of itch. Exp Dermatol 2016; 25: 750-757.

16. Akiyama T, Merrill AW, Zanotto K, Carstens MI, Carstens E. Scratching behavior and Fos expression in superficial dorsal horn elicited by protease-activated receptor agonists and other itch mediators in mice. J Pharmacol Exp Ther 2009; 329: 945-951.

17. Papoiu ADP, Tey HL, Coghill RC, Wang H, Yosipovitch G. Cowhage-induced itch as an experimental model for pruritus. a comparative study with histamine-induced itch. PLoS One 2011; 6: e17786.

18. Bromm B, Scharein E, Darsow U, Ring J. Effects of menthol and cold on histamine-induced itch and skin reactions in man. Neurosci Lett 1995; 187: 157-160.

19. Yosipovitch G, Arendt-Nielsen L, Andersen H. Itch and pain: similarities, interactions, and differences. 1st edn. Philadelphia (PA): Wolters Kluwer; 2020: Ch23 p. 277-288.

20. Heinzerling L, Mari A, Bergmann K-C, Bresciani M, Burbach G, Darsow U, et al. The skin prick test - European standards. Clin Transl Allergy 2013; 3: 3.

21. Andersen HH, Melholt C, Hilborg SD, Jerwiarz A, Randers A, Simoni $A$, et al. Antipruritic effect of cold-induced and transient receptor potential-agonist-induced counter-irritation on histaminergic itch in humans. Acta Derm Venereol 2017; 97: 63-70.

22. Weisshaar E, Ziethen B, Gollnick H. Lack of efficacy of topical capsaicin in serotonin-induced itch. Skin Pharmacol Appl Skin Physiol 2000; 13: 1-8.

23. Hosogi M, Schmelz M, Miyachi Y, Ikoma A. Bradykinin is a potent pruritogen in atopic dermatitis: a switch from pain to itch. Pain 2006; 126: 16-23.

24. Papoiu ADP, Tey HL, Coghill RC, Wang H, Yosipovitch G. Cowhage-induced itch as an experimental model for pruritus. A comparative study with histamine-induced itch. PLoS One 2011; 6: e17786.

25. Andersen HH, Marker JB, Hoeck EA, Elberling J, ArendtNielsen L. Antipruritic effect of pretreatment with topical capsaicin $8 \%$ on histamine- and cowhage-evoked itch in healthy volunteers: a randomized, vehicle-controlled, proofof-concept trial. Br J Dermatol 2017; 177: 107-116.

26. Bailer AJ. Testing for the equality of area under the curves when using destructive measurement techniques. J Pharmacokinet Biopharm 1988; 16: 303-309.

27. Werner YLVA, Lindberg M. Transepidermal water loss in dry and clinically normal skin in patients with atopic dermatitis. Acta Derm Venereol 1985; 65: 102-105.

28. Geber C, Klein T, Azad S, Birklein F, Gierthmühlen J, Huge V, et al. Test-retest and interobserver reliability of quantitative sensory testing according to the protocol of the German Research Network on Neuropathic Pain (DFNS): a multi-centre study. Pain 2011; 152: 548-556.

29. Rolke R, Baron R, Maier C, Tolle TR, Treede R-DD, Beyer A, et al. Quantitative sensory testing in the German Research Network on Neuropathic Pain (DFNS): standardized protocol and reference values. Pain 2006; 123: 231-243.

30. Olsen R V., Andersen HH, Møller HG, Eskelund PW, ArendtNielsen L. Somatosensory and vasomotor manifestations of individual and combined stimulation of TRPM 8 and TRPA1 using topical L-menthol and trans-cinnamaldehyde in healthy volunteers. Eur J Pain 2014; 18: 1333-1342.

31. Dhaka A, Viswanath V, Patapoutian A. Trp ion channels and temperature sensation. Annu Rev Neurosci 2006; 29: $135-161$.

32. Snyder LM, Kuzirian MS, Ross SE. An unexpected role for TRPV4 in serotonin-mediated itch. J Invest Dermatol 2016; 
136: 7

33. Chen Y, Fang Q, Wang Z, Zhang JY, MacLeod AS, Hall RP, et al. Transient receptor potential vanilloid 4 ion channel functions as a pruriceptor in epidermal keratinocytes to evoke histaminergic itch. J Biol Chem 2016; 291: 10252-10262.

34. Shelley WB, Arthur RP. Mucunain, the active pruritogenic proteinase of cowhage. Science 1955; 122: 469-470.

35. Shelley WB, Arthur RP. Studies on cowhage (mucuna pruriens) and its pruritogenic proteinase, mucunain. AMA Arch Derm 1955; 72: 399-406.

36. Dai Y, Wang S, Tominaga M, Yamamoto S, Fukuoka T, Higashi $T$, et al. Sensitization of TRPA1 by PAR2 contributes to the sensation of inflammatory pain. J Clin Invest 2007; 117: 1979-1987.

37. Szöllősi AG, Vasas N, Angyal Á, Kistamás K, Nánási PP, Mihály J, et al. Activation of TRPV3 regulates inflammatory actions of human epidermal keratinocytes. J Invest Dermatol 2018; 138: 365-374.

38. Vergnolle N, Hollenberg MD, Sharkey KA, Wallace JL. Characterization of the inflammatory response to proteinaseactivated receptor-2 (PAR2)-activating peptides in the rat paw. Br J Pharmacol 1999; 127: 1083-1090.

39. Vergnolle N, Wallace JL, Bunnett NW, Hollenberg MD. Protease-activated receptors in inflammation, neuronal signaling and pain. Trends Pharmacol Sci 2001; 22: 146-152.

40. Seeliger S, Derian CK, Vergnolle N, Bunnett NW, Nawroth $R$, Schmelz $M$, et al. Proinflammatory role of proteinase- activated receptor- 2 in humans and mice during cutaneous inflammation in vivo. FASEB J 2003; 17: 1871-1885.

41. Saifeddine $M$, Al-ani $B$, Cheng $C H$, Wang $L$, Hollenberg MD. Rat proteinase-activated receptor-2 (PAR-2): CDNA sequence and activity of receptor-derived peptides in gastric and vascular tissue. Br J Pharmacol 1996; 118: 521-530.

42. Boettger MK, Bär KJ, Dohrmann A, Müller $H$, Mertins L, Brockmeyer $\mathrm{NH}$, et al. Increased vagal modulation in atopic dermatitis. J Dermatol Sci 2009; 53: 55-59.

43. Seiffert K, Hilbert E, Schaechinger H, Zouboulis CC, Deter HC. Psychophysiological reactivity under mental stress in atopic dermatitis. Dermatology 2005; 210: 286-293.

44. Tran BW, Papoiu ADP, Russoniello CV, Wang $H$, Patel TS, Chan $\mathrm{YH}$, et al. Effect of itch, scratching and mental stress on autonomic nervous system function in atopic dermatitis. Acta Derm Venereol 2010; 90: 354-361.

45. Min S, Kim KW, Jung WM, Lee MJ, Kim YK, Chae $Y$, et al. Acupuncture for histamine-induced itch: Association with increased parasympathetic tone and connectivity of putamenmidcingulate cortex. Front Neurosci 2019; 13: 215.

46. Kosteletzky F, Namer B, Forster C, Handwerker HO. Impact of scratching on itch and sympathetic reflexes induced by cowhage (Mucuna pruriens) and histamine. Acta Derm Venereol 2009; 89: 271-277.

47. Kirchner A, Stefan H, Schmelz M, Haslbeck KM, Birklein F. Influence of vagus nerve stimulation on histamine-induced itching. Neurology 2002; 59: 108-112. 